\title{
Erratum to: Peilingmelkvoeding van zuigelingen in 2018
}

\author{
P. van Dommelen · O. Engelse
}

Published online: 21 juni 2021

(C) Bohn Stafleu van Loghum is een imprint van Springer Media B.V., onderdeel van Springer Nature 2021

\section{Erratum}

\section{Tijdschr Jeugdgezondheidsz 2021}

https://doi.org/10.1007/s12452-021-00251-w

In dit artikel ontbrak de Engelstalige samenvatting.

\begin{abstract}
Introduction: For monitoring and evaluation of breastfeeding policy, it is important to conduct regular surveys on infant milk feeding. Between the year 2001 and 2015, seven surveys using questionnaires were conducted in the Netherlands. Our aim is to conduct a survey of the year 2018 using data from the electronic health care records of the Dutch preventive child health care (CHC).

Method: Seven CHC organizations provided data on milk feeding from 2018. Descriptive statistics and chisquare tests were performed.

Results: In total, data were available from approximately 24,000 infants on the day of birth and the 8th day, 19,000 between 2 weeks and 3 months, 15,000 at 6 months, 7,000 at 9 months and 4,000 at 12 months. The distribution of background characteristics was similar to that of the national figures. The proportion of infants who were breastfed at birth, 8th day, 2 weeks,
\end{abstract} $1,3,6,9$ and 12 months in 2018 were $69 \%, 58 \%$,
$56 \%, 47 \%, 31 \%, 19 \%, 21 \%$ and $9 \%$, respectively. At all ages, these proportions were significantly $(p<0.01$ and $\geq 5 \%$ difference) higher in infants of highly educated mothers, foreign-born (mother or infant), infants with a birth weight $\geq 2,500$ grams, gestational age $\geq 37$ weeks, and singletons. The proportion of infants who were breastfed on the day of birth was lower in 2018 than in previous surveys (2001 to 2015, 74-81\%). The proportions at 1, 3 and 6 months were almost similar to those in the surveys between 2001 and 2010, but were lower than those in the 2015 survey. Conclusion: The Dutch figures on infant milk feeding offer room for improvement, especially with regard to starting breastfeeding. It is recommended to support (expectant) mothers in their decisions on breastfeeding. It is also important that the various healthcare professionals involved continue to talk to (expectant) mothers about starting breastfeeding, and discuss potential problems and solutions regarding continuing breastfeeding.

Dr. P. van Dommelen, statisticus, onderzoeker

O. Engelse, adviseur

De online-versie van de originele bijdrage vindt $u$ onder https://doi.org/10.1007/s12452-021-00251-w.

Dr. P. van Dommelen $(\bowtie)$

TNO Child Health, Leiden, Nederland

Paula.vanDommelen@tno.nl

O. Engelse

Nederlands Centrum Jeugdgezondheid, Utrecht, Nederland 